\title{
Retrofitting of a Residential District under Near Zero Energy Buildings Criteria ${ }^{\dagger}$
}

\author{
Miguel Á. García-Fuentes ${ }^{1, *}$, Ignacio González ${ }^{2}$, Alfonso Gordaliza ${ }^{3}$ and Cristina de Torre ${ }^{1}$ \\ 1 Fundación CARTIF, Valladolid 47151, Spain; critor@cartif.es \\ 2 Acciona Construcción, Madrid 28108, Spain; Ignacio.gonzalez.perez.ext@acciona.com \\ 3 Veolia Servicios LECAM, Valladolid 47009, Spain; alfonso.gordaliza@veolia.com \\ * Correspondence: miggar@cartif.es \\ + Presented at the Sustainable Places 2017 (SP2017) conference, Middlesbrough, UK, 28-30 June 2017.
}

Published: 8 November 2017

\begin{abstract}
With the aim of achieving a Near Zero Energy District, a series of interventions have been designed focusing on improving the sustainability of the FASA neighborhood in Valladolid, increasing its energy efficiency and reducing the $\mathrm{CO}_{2}$ emissions of its buildings. In order to achieve this objective, the REMOURBAN project will act on the envelope of its buildings, on their illumination and it will modify the thermal installations to replace the current fossil fuels by renewable sources, for both heating and domestic hot water. These actions will make Valladolid a smart city benchmark with interventions in the energy, mobility and ICT sectors.
\end{abstract}

Keywords: district; envelope; biomass; energy efficiency; smart city

\section{Background}

The sustainable development of urban areas is a key challenge for Europe where the retrofitting of its buildings and, more specifically, its thermal retrofitting takes on special importance. In Spain, more than half of the buildings are built without adequate thermal insulation, which means a very high energy consumption and mostly from fossil fuels which exacerbates the problem of external energy dependence. In order to deal with this situation, projects such as REMOURBAN are demonstrating innovative, efficient and accessible technologies and processes in districts whose energy problems are evident in order to achieve Near Zero Energy Districts that serve as a reference and allow the replicability of this type of actions in other similar neighborhoods, improving the environment and the quality of life of citizens.

\section{Description of the Project}

REMOURBAN is a large scale demonstration project, whose purpose is to accelerate the urban transformation towards the smart city concept taking into account all aspects of sustainability. Several objectives will be achieved, being the most relevant the development of a holistic and replicable model for sustainable urban regeneration, with a jointly approach in the sectors of energy, mobility and ICTs.

This urban regeneration model will be developed and validated in three lighthouse cities (Valladolid-Spain, Nottingham-UK and Tepebaşı/Eskisehir-Turkey) accelerating the deployment of innovative technologies, organisational and economic solutions to significantly increase resource and energy efficiency, improve the sustainability of urban transport and drastically reduce greenhouse gas emissions.

In Valladolid, the FASA neighborhood has been selected for the implementation of a set of interventions designed in order to achieve this neighborhood become a Near Zero Energy District. 
This neighborhood was built during the 60s for the workers of the Renault factory in Valladolid, and it is composed by 19 blocks, a tower and a building that contains the thermal power station that supplies heating to the 398 homes that make up the neighborhood. These buildings present severe deficiencies in their thermal insulation that result in lack of habitability and comfort, as well as low energy efficiency.

The heating system consists of a district network supplied by two fossil fuel boilers (natural gas and heating-oil) and it is divided into three different circuits that provide the 398 dwellings with space heating, whereas the domestic hot water (DHW) is individually produced in each dwelling with different technologies depending of the energy source in each particular case: natural gas, butane and electricity.

In REMOURBAN, with the aim of turning the neighborhood into an Near Zero Energy District, a set of actions have been designed to modify both the building envelope and the current thermal generation systems.

\section{Methodology}

The methodology used is based on the development of energy simulations (and non-destructive tests) of the district and its corresponding validation using real data of consumption for the subsequent evaluation of the design alternatives.

\subsection{Energy Simulation and Non-Destructing Testing}

Design Builder was the tool chosen both to develop the energy model and to run the energy simulations and the subsequent calibration of the baseline and the retrofitted building models. This software contains Energy + as simulation engine, which allows to run dynamic analysis of the building during the whole year. The result is a detailed assessment of the building energy behavior and the internal thermal comfort.

As mentioned before, the district contains 19 blocks of 5 stories and a tower of 14 stories. The blocks are groping among the neighborhood district following three typologies. Due to the size of the case of study, it is not possible to generate an energy model of the whole neighborhood. Therefore, it is necessary to select some representative buildings to address the energy simulations, and afterwards, extrapolate the results to the whole district. Therefore, after considering the different typologies taking into account height, orientation, dwelling surface, etc. The buildings selected were:

- (A) The 14 stories tower, based on its singularity.

- (B) Grouping blocks 9-10-11-12: Representing typology 1.

- $\quad$ (C) Block 17: Representing typology 2 and 3.

- They are represented in the Figure 1 in grey.

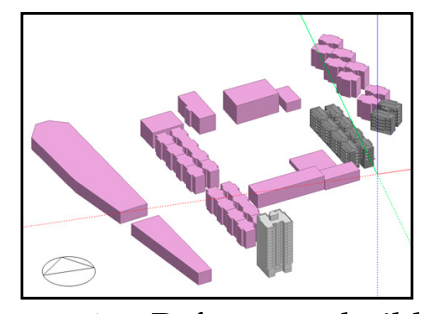

Figure 1. Reference buildings considering the three different typologies

\subsection{Definition of the Interventions}

The interventions over the building envelope (external thermal insulation cladding system on the façades; roof insulation over last concrete slab in the blocks; inverted roof in the tower) are focused in the improvement of buildings energy behavior and the thermal comfort of the tenants, through passive solutions economically affordable and with high impact the energy demand.

In addition to the heating savings, REMOURBAN project aims the integration of RES. To address this objective, it is going to be installed a photovoltaic ventilated façade in the south façade of the 14 stories tower. This system will produce enough electricity to cover around the $25 \%$ of the domestic hot water consumption of this building. 
Finally, the electricity consumption of the buildings will be also reduced by the renovation of the lightning system of building common areas by LED technology.

The interventions related to the new district network for space heating and DHW are aimed to reduce energy consumption at district level, integrate renewable energy sources mitigating the environmental impact and implement ICT and monitoring tools for a better control and operation of the facilities. The most remarkable actions are described below:

- Full renovation of the thermal station, including the installation of new two biomass-fired boilers that will cover around the $80 \%$ of the thermal energy demand of the district, keeping one of the original gas-fired boilers as back-up in case of breakdown or peaks of consumption. The biomass will be wood chips obtained from pruning and cleaning of forests in the region minimizing the environmental impact and the transport costs.

- Installation of variable flow pumping units at district and building levels that allow adapting the energy production to the real demand and schedules of the end users.

- Refurbishment of the distribution network, deploying new pre-insulated pipes with a leak detection system that will optimise the transmission from the thermal station to the buildings. In addition, the flow temperature and pressure are significantly reduced by changing the operation from superheated water $\left(>100^{\circ} \mathrm{C}\right)$ to hot water $\left(80-90^{\circ} \mathrm{C}\right)$ which has a great impact minimizing the heat losses and operational risks in the distribution system.

- Complete renovation of the thermal substations in order to optimize the heat exchange process inside the buildings, including new high-efficient heat exchangers, pumps, valves, etc.

- Integration of the individual DHW systems in the same district network, including a DHW tank in each building substation, reducing the costs and the energy bill.

- Implementation of thermostatic valves, smart individual thermostats and heat cost allocators at home level, contributing to individual energy savings while improving the thermal comfort level inside the houses.

- Heat smart meters will be installed at district and building levels in order to have a precise metering of the thermal consumption (both space heating and DHW). Together with the heat cost allocators at dwelling level this will allow to monitor the performance of the different energy stages (generation, distribution and consumption), giving the possibility of building billing or even individual billing.

- Design and development of operation strategies based on smart control systems that will enable a real-time follow-up and continuous improvement of the energy performance of the whole system.

\section{Results and Obtained Data}

In the following table is shown the heating demand and consumption of the simulated buildings and the extrapolation to the whole district, before and after the proposed intervention. 

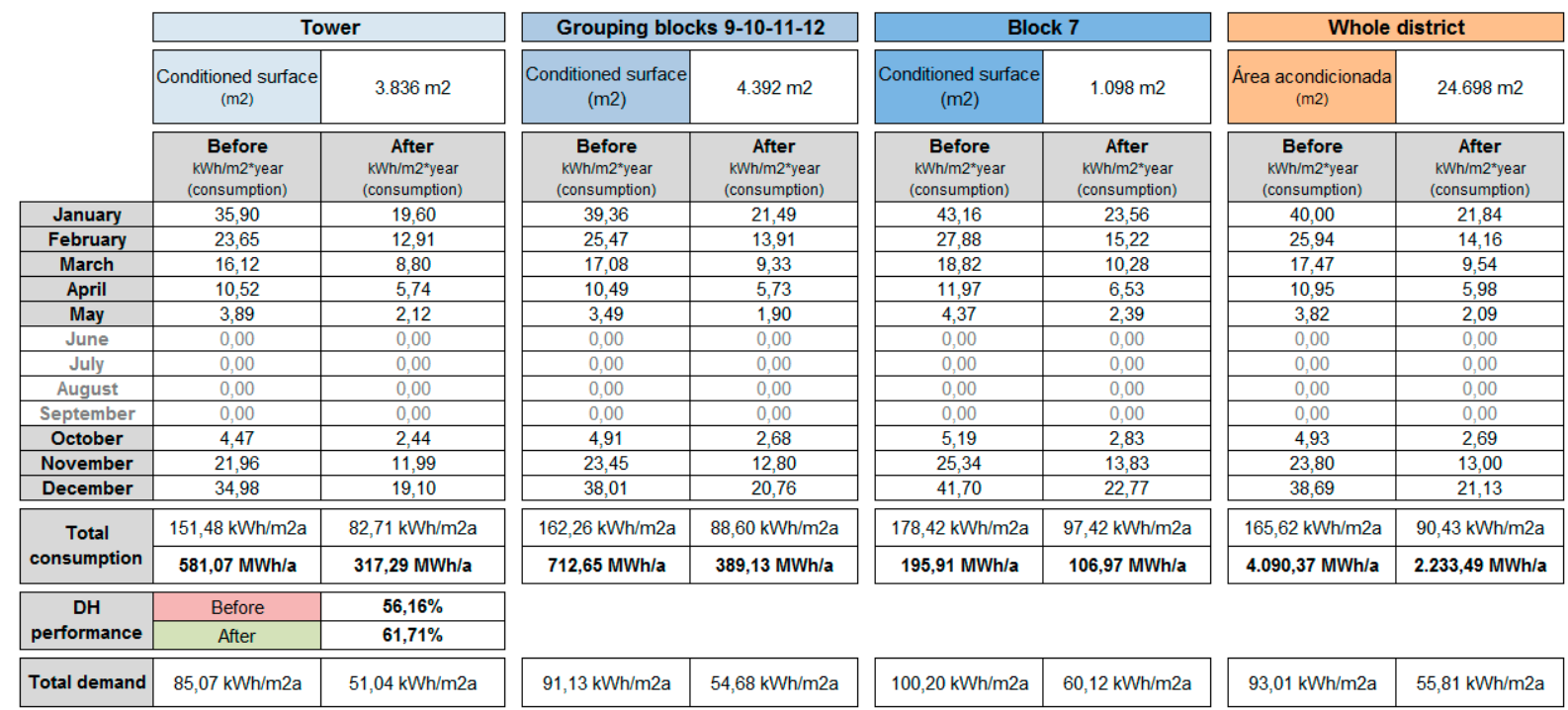

Operational values are the same in the base case than in the retrofitted case, because they are not affected by the intervention. It should be noted that whole district heating demand is reduced from $93.01 \mathrm{kWh} / \mathrm{m}^{2}$.year to 55.81 (40\% savings) just due to the envelope insulation. The performance of the district heating improves from 56.16 to $61.77 \%$ thanks to the renovation of the boilers, distribution network and building substations.

Both measures, passive and active, result in a reduction of the whole district heating consumption from $165.62 \mathrm{kWh} / \mathrm{m}^{2}$.year to $90.34 \mathrm{kWh} / \mathrm{m}^{2}$ (45.4\% savings). This reduction in the demand, together with the change of fossil fuels by biomass, turn the district in a nearly zero $\mathrm{CO}_{2}$ emissions area.

\section{Conclusions}

Through the generation of calibrated simulation models it is possible to identify and evaluate with greater accurate the possibilities of implementing energy conservation measures, where assessing the district dimension (including energy interactions between buildings) is key to being able to carry out Integral interventions that balance the behavior of the whole as a single energy unit. This also allows for a more accurate assessment of the business models and financial schemes, reducing risks by obtaining a more accurate identification of the medium and long-term benefits, especially for the users of the dwellings, who must be part of the design process through a strong citizen engagement strategy.

Acknowledgments: Part of the work presented in this paper is based on the research conducted within the project "Regeneration Model for Accelerating the Smart Urban Transformation-REMOURBAN", which has received funding from the European Union Horizon 2020 Framework Program (H2020/2014-2020) under Grant Agreement No. 646511.

Author Contributions: The REMOURBAN Methodology applied in the FASA district with the aim of turning the neighborhood into an Near Zero Energy District, was conceived through a collaborative work among CARTIF Foundation, ACCIONA Construcción S.A. and VEOLIA Servicios LECAM. As written contributions for this article, Cristina de Torre and Miguel Ángel García analyzed the background and described the project and citizen engagement strategy in the retrofitting process; Ignacio González defined the methodology followed and the interventions over the building envelope. Alfonso Gordaliza described the interventions that will be carried out in the new district network for space heating and DHW.

Conflicts of Interest: The authors declare no conflict of interest. 


\section{References}

1. García-Fuentes, M.A.; Pujols, C.; García-Pajares, R.; Vasallo, A.; Martín, A. Metodología de Rehabilitación Energética hacia Distritos Residenciales de Energía Casi Nula. Aplicación al barrio del Cuatro de Marzo (Valladolid). In Proceedings of the II Congreso EECN, Madrid, Spain, 7 May 2013.

2. Meiss, A.; Del Caz, R.; Álvaro, A. Rehabilitación de Barrios de Vivienda Social. El ARI de la Rondilla en Valladolid. Ciudad y Territorio. Estudios Territoriales CyTET XLV (175) 2013; Ministerio de Fomento: Madrid, Spain, 2013.

3. AAVV; Potencial de Ahorro Energético y de Reducción de Emisiones de $\mathrm{CO}_{2}$ del Parque Residencial Existente en España en 2020; World Wildlife Fund (WWF): Madrid, Spain, 2010.

(c) 2017 by the authors. Licensee MDPI, Basel, Switzerland. This article is an open access article distributed under the terms and conditions of the Creative Commons Attribution (CC BY) license (http://creativecommons.org/licenses/by/4.0/). 